DOI 10.37882/2223-2982.2020.11.33

\title{
ФОРМИРОВАНИЕ ИНОЯЗЫЧНОЙ ИНФОРМАЦИОННОЙ КОМПЕТЕНЦИИ В КУРСЕ ОБУЧЕНИЯ ФРАНЦУЗСКОМУ ЯЗЫКУ БУДУЩИХ ЭКОНОМИСТОВ-МЕЖДУНАРОДНИКОВ (ПРОДВИНУТЫЙ ЭТАП)
}

\section{FORMING FOREIGN LANGUAGE INFORMATION COMPETENCE WHILE TEACHING THE FRENCH LANGUAGE TO FUTURE INTERNATIONAL ECONOMISTS (ADVANCED LEVEL)}

\section{N. Selivanova \\ A. Shashurina \\ L. Chitakhova}

Summary: The article examines how important it is to train students information competence at the advanced level using the French language teaching to future specialists in international economic relations as an example. Information competence, one of the key educational competencies, has many definitions, which do not contradict each other, though. Mastering information technologies that provide effective search for information as well as motivational and value-oriented attitude to information activities and ability to work with foreign language information flows develop a person's information culture. Forming information competence by means of foreign language teaching makes a significant contribution to the development of students' ability to meaningfully perceive the required information, analyze and process it accordingly.

Keywords: foreign language information competence, information competence, information and communication technologies, information activity of a person, formulation of a hypothesis, semantic processing of content.
Селиванова Наталья Алексеевна

К.n.н., доцент, Московский государственный институт международных отношений (Университет) МИД России nata2008_54@mail.ru

Шамурина Алла Юрьевна

К.филол.н., доцент, Московский государственный институт международных отношений

(Университет) МИД России allashashurina@yandex.ru

читахова Любовь Лусегеновна

К.филол.н., дочент, Московский государственный институт международных отношений

(Университет) МИД России I.chitakhova@my.mgimo.ru

Аннотация: В статье рассматривается важность формирования информационной компетенции у студентов продвинутого этапа обучения на примере преподавания французского языка будущим специалистам в области международных экономических отношений. Информационная компетенция - одна из ключевых образовательных компетенций, имеющая множество определений, которые, тем не менее, не противоречат друг другу. И владение информационными технологиями, обеспечивающими эффективный поиск информации, и мотивационно-ценностное отношение к информационной деятельности, и умение работать с иноязычными информационными потоками развивают информационную культуру личности. Формирование информационной компетенции средствами предмета иностранный язык вносит существенный вклад в развитие способности обучаемых осмысленно воспринимать искомую информацию, анализировать и соответствующим образом её обрабатывать.

Ключевые слова: иноязычная информационная компетенция, информационная компетенция, информационно-коммуникативные технологии, информационная активность личности, формулировка гипотезы, смысловая обработка содержания. реимущество компетентностного подхода к обучению иностранному языку в вузе заключается в том, что он максимально приближает студентов к непосредственному и опосредованному общению с зарубежными коллегами в будущей профессиональной деятельности. Занятия, организованные в русле компетентностного и коммуникативно-деятельностного подхода на продвинутом этапе обучения позволяют не только моделировать реальную практику делового общения, разнообразные аспекты профессиональной деятельности будущего специалиста, но и проблемно заострить и интеллектуально обогатить межкультурную деловую коммуникацию с носителями языка.

Федеральный государственный образовательный стандарт высшего образования предполагает формирование у студентов-бакалавров целого ряда общеучебных и профессионально-специализированных компетенций. Образовательная компетенция представляет собой совокупность взаимосвязанных качеств личности (знаний, умений, навыков, способов и опыта деятельности), включённых в состав образовательных областей и учебных предметов, необходимых для осуществления личностно и социально-значимой продуктивной де- 
ятельности [10, с. 4]. Перечень образовательных компетенций, их структурно-содержательное наполнение продолжают актуализироваться и уточняться. Развиваемые компетенции представляют собой «предпосылку и основу формирования компетентности как интегративного, базирующегося на знаниях, интеллектуально и социокультурно обусловленного личностного качества, проявляющегося в деятельности, поведении человека, в его взаимодействии с другими людьми в процессе решения разнообразных профессиональных задач» [5, с. 9].

Информационная компетенция общепризнанно является одной из ключевых образовательных компетенций.

В научной литературе термин «информационная компетенция» представлен множественностью трактовок и дефиниций, от самых сжатых и лаконичных до более подробных и развёрнутых. Авторы делают акцент на разных сущностных характеристиках и компонентах информационной компетенции. Нередко термины «компетенция» и «компетентность» рассматриваются как взаимозаменяемые. В дальнейшем в статье мы будем оперировать понятием «информационная компетенция», рассматривая компетентность как некий обобщающий интегративный результат образовательного процесса, как сформированное «умение решать социально-профессиональные задачи в деятельности на основе освоенного содержания учебных дисциплин при актуализации необходимых для её успешности личностных качеств» $[5$, с. 10].

Что касается определений информационной компетенции, предлагаемых разными исследователями, то они могут быть сгруппированы по нескольким критериям:

1. Большая часть специалистов совершенно правомерно связывает понятие информационной компетенции (компетентности) с применением мультимедийных, информационно-коммуникационных технологий как неотъемлемого инструмента поиска необходимой информации. В их интерпретации информационная компетенция, это интегративное качество, характеризующееся высоким уровнем теоретических знаний и практических умений в области информационных технологий, способностью применять эти знания и умения в процессе освоения основной образовательной программы высшего профессионального образования, готовностью использовать компьютерные технологии в профессиональной деятельности» [3, с. 122]. Высокая компьютерная грамотность, информационная активность личности, умение ориентироваться в информационном сетевом пространстве с помощью новейших технических средств и приёмов, вне всякого сомне- ния, делают более эффективным процесс сбора, обработки и хранения профессионально значимой информации.

2. Отдельная группа учёных и исследователей даёт более общую трактовку информативной компетенции и характеризует её как «сложное индивидуально-психологическое образование на основе интеграции теоретических знаний, практических умений в области инновационных технологий и определённого набора личностных качеств» [4, с. 14]. При таком подходе акцентируется мотивационно-ценностный компонент информационной деятельности, на первый план выдвигается осознание студентами личностной и социальной значимости информации [6].

3. Исследователи, работающие в области лингводидактики и методики преподавания иностранных языков, в качестве главного объекта изучения рассматривают способность будущих специалистов работать с иноязычными информационными потоками, что неизбежно связано с поиском, обработкой и трансформацией искомой информации на иностранном языке [8, с. 1]. О.В. Флёров, характеризуя иноязычную парадигму информационной компетенции, полагает, что это «совокупность когнитивных качеств, обеспечивающих способность человека производить различные операции с информацией, а также вступать в различные виды взаимодействия в условиях увеличивающихся информационных потоков [9, с. 55.]. Анализируя качество современного электронного пространства как основного информационного ресурса для преподавателей иностранных языков, О.В. Флёров замечает, что в современном Интернете, к сожалению, много непроверенной, неподкреплённой фактами, неаргументированной информации, что неизбежно потребует её осмысленного отбора и оценки её полезности и пригодности к использованию для решения задач профессиональной деятельности.

Принимая во внимание и обобщая позиции различных исследователей, мы вправе говорить об информационной компетенции как о составной части более общей категории, а именно об информационной культуре личности, которая становится важнейшей частью базисной культуры, «частью системной характеристики человека, позволяющей ему эффективно участвовать во всех видах работы с информацией» [7, с. 55]. В контексте исследуемой в статье проблематики, следует подчеркнуть, что информационная культура становится неотъемлемой частью профессиональной культуры экономистов, специализирующихся в области международных экономических отношений.

В последние годы наметилась неутешительная для 
преподавателей иностранного языка тенденция, связанная с поиском студентами проблемно-тематической текстовой информации в учебных целях (для подготовки докладов, сообщений и т.д.). Для многих студентов этот поиск сводится к использованию ключевого слова и введению запроса в поисковой системе интернета. Критерии отбора найденной информации практически отсутствуют, а главное, нет критического осмысления надёжности и достоверности используемого источника. Подход к отбору материала носит, таким образом, формальный характер и содержание его не осмысливается должным образом.

Сама форма использования студентами текстового материала, как правило, носит компилятивный характер. Зачастую в таких текстах отсутствуют связность изложения, логика, аргументированная авторская позиция. Гораздо реже студенты используют аутентичные статьи из периодической печати, интернет-версии известных печатных СMИ (Le Monde, La Tribune, Les Échos и др.). И этому есть объяснение. Во-первых, аутентичный (газетный) дискурс отличается сложной многокомпонентной и многоуровневой структурой. Организационная структура статьи со всей её иерархией заголовков, подзаголовков, абзацев, подтверждающих цитат, иллюстративных материалов требует внимательного рассмотрения, так как все эти структурные элементы не случайны, у каждого из них своя смысловая нагрузка, и все они помогают читателю адекватно воспринять основное содержание и облегчают поиск релевантной информации. Во-вторых, лингвокультурологическая и стилистическая составляющие аутентичных медиатекстов, представленные эпитетами, метафорами, игрой слов, сравнениями, лексикой с национально-культурной семантикой, создают дополнительную сложность для понимания содержания прочитанного. В-третьих, студентам не хватает фоновых знаний: общечеловеческих, региональных и страноведческих [2, с. 11], чтобы адекватно понять и истолковать «социо-культурный фон, характеризующий воспринимаемую [письменную] речь» [1, с. 49].

При анализе исследований PISA (Programme for International Student Assessment), международной программы по оценке образовательных достижений учащихся, было установлено, что российские учащиеся показали спад читательской грамотности'. Они не очень хорошо умеют работать с информацией: сопоставлять разрозненные фрагменты, соотносить общее содержание с его конкретизацией, текстовую информацию с внетекстовой, целенаправленно искать недостающую информацию; зачастую не владеют навыками целостного, творческого анализа, целеполагания, постановки гипотез.

Таким образом, формирование информационной компетенции приобретает большую значимость, осо- бенно в курсе обучения французскому языку на продвинутом этапе, когда общий уровень владения языком уже достаточно высок.

Вернёмся к определению информационной компетенции и уточним его применительно к конкретным задачам, стоящим перед преподавателями иностранного (в нашем случае, французского) языка, работающими на старших курсах с будущими экономистами-международниками.

С учётом перспективы будущей профессиональной деятельности, где иностранному языку отводится немаловажная роль (как языку делового общения, средству интеллектуально-коммуникативного взаимодействия), это определение может быть сформулировано следующим образом: иноязычная информационная компетенция - это способность специалиста самостоятельно находить, осмысленно воспринимать, оценивать на предмет целесообразности ознакомления, анализировать и соответствующим образом обрабатывать необходимую информацию, а также обмениваться ею со своими зарубежными коллегами в непосредственном и опосредованном деловом и личном общении.

В этом определении можно условно выделить две самостоятельные части. В первой части акцент сделан на поиск, осмысление и анализ информации, на целесообразность знакомства с нею для дальнейшего её использования. Во второй части подчёркивается необходимость её обработки, включения в устное или письменное высказывание в рамках профессионального, делового и личностного общения. С методической точки зрения и с позиций компетентностного подхода, это очень важный момент. Осознанно отобранная в тех или иных целях информация находит своё применение в создании разного по форме, содержанию и целевой направленности текстового продукта: отчёта, выступления, доклада, реферата, устного и письменного обмена мнениями по самым актуальным вопросам экономической и общественной жизни.

Формирование информационной компетенции в курсе обучения французскому языку на продвинутом уровне является основной целью учебного пособия «La France. Réalités régionales» («Франция в региональном измерении») для бакалавриата и магистратуры экономического профиля [11].

Пособие состоит из трёх блоков, посвящённых социально-экономическим проблемам трёх регионов Франции: Иль-де-Франс (Ile-de-France), БургундииФранш-Конте (Bourgogne-Franche-Comté) и О-де-Франс (Hauts-de-France). Каждый блок учебного пособия включает три самостоятельных раздела: 
I. Aux abords de l'lle-de-France / Aux abords de la Bourgogne-Franche-Comté / Aux abords des Hauts-deFrance (На подступах к Иль-де-Франс, Бургундии-ФраншКонте, О-де-Франс).

II. À travers l'lle-de-France / À travers la BourgogneFranche-Comté / À travers les Hauts-de-France (Ha просторах Иль-де-Франс / Бургундии- Франш-Конте, О-деФранс).

III. Mosaïque francilienne / bourguignonne et franccomtoise / Mosaïque des Hauts-de-France (Мозаика Ильде-Франс, Бургундии-Франш-Конте, О-де-Франс).

С точки зрения региональной тематики, эти три раздела соответствуют:

- проблемам, актуальным для каждого региона в том, что касается его истории и его современного состояния;

- социально-экономической характеристике региона в целом;

- информации об отдельных ключевых проблемах, с которыми сталкивается конкретный регион (Городской транспорт в XXI-ом веке: вызовы и перспективы развития; Региональные экологические проблемы и пути их решения; Обустройство территории: преобразование бывших производственных и промышленных зон; Миграционный кризис: поиск способов урегулирования).

Раздел, в свою очередь, подразделяется на части, каждая из которых несёт собственную функциональную нагрузку и в плане презентуемой информации и в плане обучения её толкованию, оценке, содержательной и языковой обработке.

Первый раздел каждого блока («На подступах к...») состоит из двух частей.

На текстовом материале первой части развивается умение студентов формулировать гипотезу относительно содержания газетной или журнальной публикации, основываясь на сравнительно небольшом объёме информации (заголовке, подзаголовке, вступительной части статьи). Известно, что заголовок и подзаголовок играют не только важнейшую роль в привлечении внимания читателей. Это своего рода предтекст, свёрнутый и лаконичный по форме, но зачастую очень ёмкий по содержащейся в нём эксплицитной и имплицитной информации, а в силу использования метафорических оборотов речи, броский и яркий по своему эмоциональному воздействию на реципиента. Задача преподавателянаучить студентов извлекать максимум фоновой страноведческой информации из структурных элементов статьи, не относящихся к её основному корпусу, прогнозировать содержание, определять авторскую позицию и тональность текста.

На текстовом материале второй части раздела формируется умение распознавать и вычленять логическую структуру текста статьи. Логическая упорядоченность информации, содержащейся в аутентичном тексте, всегда имеет свои особенности. Авторские рассуждения, пояснительные замечания, заключения и выводы перемежаются логическими коннекторами, языковыми единицами, обеспечивающими когерентность и связность текстового изложения. Соединительные элементы письменной речи обеспечивают полноту восприятия информации, которую автор хочет донести до читателя, а также позволяют проследить ход рассуждений и авторскую аргументацию в раскрытии той или иной мысли. На этом этапе работы преподаватель уделяет повышенное внимание логической структуре статьи и языковым средствам, обеспечивающим логичность подачи информации.

Второй раздел каждого блока («На просторах...») также состоит из двух частей.

Первая часть посвящена обучению стратегиям чтения целого текста, нахождению ключевых элементов и методам структурирования содержащейся в нём информации.

Вторая часть нацелена на обучение методам смысловой обработки и презентации (в устной и письменной форме) информации, заключённой в целом тексте (или в нескольких текстах). В каждом последующем блоке целью обучения становится новый способ обработки текста.

Третий раздел каждого блока (региональная проблемно-тематическая мозаика) имеет целью обучение методике составления и представления в должной форме устного развёрнутого сообщения (Exposé oral) по определённой проблематике, связанной с реалиями социально-экономической жизни современной Франции. Это умение является синтетическим и предполагает использование разнообразных навыков работы с текстом статьи, поэтому формируется поэтапно. Задания этого раздела в некотором роде суммируют виды работы, предложенные в двух первых разделах всех трёх блоков, а входящие в его состав проблемно-тематические прессдосье предназначены для тренировки, закрепления и контроля уровня сформированности этих навыков.

В учебном пособии решаются задачи по развитию следующих умений:

- определять ключевые (опорные) речевые единицы как в отдельном тексте статьи, так и в нескольких тематически связанных между собой статьях;

- структурировать текст и определять логическую 
взаимосвязь и взаимодополняемость его отдельных частей;

- распределять информацию по степени её значимости (основная / второстепенная);

- представлять информацию, содержащуюся в тексте в виде краткого и / или развёрнутого плана;

- развёртывать и свёртывать информацию на уровне отдельного предложения, абзаца и целого текста;

- различать субъективность подхода автора статьи к излагаемой им информации или проблеме и изложенные им объективные факты и сведения;

- сопоставлять отдельные источники информации с целью нахождения общих, повторяющихся и / или различающихся тезисов (высказываний).

Перечисленные умения развивают у обучающихся способность представлять содержание текста статьи в краткой форме, строго следуя логике текста-оригинала (résumé) и сокращённой форме, но не обязательно сохраняя логику повествования оригинального текста статьи (compte-rendu), синтезировать информацию, содержащуюся в нескольких статьях (synthèse), анализировать и объективно представлять точку зрения автора текста (analyse), интерпретировать авторскую позицию и высказывать собственное мнение по конкретной проблеме (commentaire), самостоятельно составлять проблемнотематическое досье (dossier thématique) и представлять его содержание в виде развёрнутого сообщения-доклада (exposé oral).

Все вышеперечисленные навыки смысловой обработки текстового материала, формируемые в процессе обучения французскому языку на продвинутом этапе, смогут найти непосредственное применение в будущей профессиональной деятельности студентов (магистрантов).

\section{ЛИТЕРАТУРА}

1. Ахманова 0.С., Гюббенет И.В. «Вертикальный контекст» как филологическая проблема. // Вопросы языкознания. - 1977. - № 3.

2. Верещагин Е.М., Костомаров В.Г. Язык и культура // М.: Индрик, 2005.

3. Грибан 0.Н. Формирование информационной компетентности студентов педагогического вуза. Монография. // М-во образования и науки Российской Федерации, Федеральное гос. бюджетное образовательное учреждение высш. проф. образования «Уральский гос. пед. ун-т», Ин-т социального образования. - Екатеринбург: УрГПУ, 2015.

4. Зайцева 0. Б. Формирование информационной компетентности будущих учителей средствами инновационных технологий: Автореф. дис. ... канд. пед. наук. Брянск, 2002. - 19 с.

5. Зимняя И.А. Компетенция и компетентность в контексте компетентностного подхода в образовании // Иностранные языки в школе. - 2012. - № 6.

6. Каменев К.В., Мовчан И.Н. Структура информационной компетентности // Гуманитарные научные исследования. - 2015. - № 7. Ч. 1. [Электронный ресурс] http://human.snauka.ru/2015/07/11937 (дата обращения: 05.09.2020)

7. Каракозов С.Д. Информационная культура в контексте общей теории культуры личности. Педагогическая информатика. - № 2. - 2000. - С. 41-55.

8. Печинская Л.И. Формирование иноязычной информационной компетенции у студентов технических вузов в рамках дисциплины «Иностранный язык»: Автореферат диссертации на соискание ученой степени кандидата педагогических наук. Библиотека авторефератов и диссертаций по педагогике http://nauka-pedagogika.com/pedagogika-13-00-08/dissertaciya-formirovanie-inoyazychnoy-informatsionnoy-kompetentsii-u-studentov-tehnicheskihvuzov\#ixzz6bsDkSoPM: 13.00.08 / Печинская Лариса Игоревна - Санкт-Петербург, 2011.

9. Флёров 0.В. Иноязычная информационная компетенция в образовательном пространстве цифрового века: структурно-содержательный и методический анализ // Образовательные ресурсы и технологии. - № 2 (23). - 2018.

10. Хуторской А.В., Хуторская Л.Н. Компетентность как дидактическое понятие: содержание, структура и модели конструирования // Проектирование и организация самостоятельной работы студентов в контексте компетентностного подхода: Межвузовский сб. науч. тр. / Под ред. А.А. Орлова. - Тула: Изд-во Тул. гос. пед. ун-та им. Л.Н. Толстого, 2008. - Вып. 1.

11. Селиванова Н.A., Шашурина A.Ю. La France. Réalités régionales : Учебное пособие по французскому языку для бакалавриата и магистратуры экономического профиля / уровень В2-С1 / Москва, Прометей, 2020. - 185 С.

\footnotetext{
( С Селиванова Наталья Алексеевна (nata2008_54@mail.ru), Шашурина Алла Юрьевна (allashashurina@yandex.ru), Читахова Любовь Лусегеновна (I.chitakhova@my.mgimo.ru).

Журнал «Современная наука: актуальные проблемы теории и практики»
} 